\title{
COMPETÊNCIAS PROFISSIONAIS DO BIBLIOTECÁRIO ESCOLAR: REFLEXÕES A PARTIR DA LEI 12.244/10
}

\author{
HABILIDADES PROFESIONALES DE BIBLIOTECARIA DE LA \\ ESCUELA: REFLEXIONES DE LA LEY 12.244/10
}

\begin{abstract}
Ana Cristina de Albuquerque - albuanati@uel.br Doutora em Ciência da Informação pela Universidade Estadual Paulista (UNESP/Marília). Professora do Programa de Pós-Graduação em Ciência da Informação da Universidade Estadual de Londrina (UEL).

Conceição Aparecida Tedesqui - conceicaotedesqui@yahoo.com.br Especialista em Gestão de Biblioteca Escolar pela Universidade Estadual de Londrina - UEL.
\end{abstract}

\begin{abstract}
RESUMO
Introdução: Refere-se ao tripé Biblioteca Escolar, Competências do Bibliotecário e a lei 12.244/10 que dispõe sobre a universalização das bibliotecas escolares. Reflete a situação conflituosa da realidade da maioria das Bibliotecas Escolares e a ausência do profissional Bibliotecário.

Objetivo: Almeja analisar a importância das competências profissionais desenvolvidas pelo Bibliotecário escolar. Indaga-se qual o pensamento e visão que os profissionais de Bibliotecas escolares, Bibliotecários ou não, possuem a respeito da Lei.

Metodologia: Utilizou-se a pesquisa exploratória e descritiva e com abordagem qualitativa, no qual $o$ instrumento de pesquisa consistiu em um questionário, aplicado aos funcionários responsáveis pelas Bibliotecas Escolares participantes da pesquisa.

Resultados: Os profissionais atuantes nas bibliotecas das instituições investigadas possuem formação superior em variados cursos, onde de 20 bibliotecas, somente 10, contam com 0 profissional bibliotecário. Os entrevistados em sua maioria concordam com a importância de um bibliotecário formado e que a concretização da Lei 12.244/10 deverá ser fiscalizada, pois não se encontra regulamentada.

Conclusões: Considera-se que o profissional Bibliotecário muitas vezes sofre com os conceitos generalizados por parte daqueles que desconhecem a profissão. Porém, a Lei sugere uma expectativa de melhoria, isso se aplicada e requerida pelos cidadãos.
\end{abstract}

Palavras-Chave: Biblioteca Escolar. Competência Profissional. Bibliotecário Escolar. Lei $12.244 / 10$. 


\section{INTRODUÇÃO}

É sabido que a Biblioteca Escolar, mesmo perante a importante função de auxiliar na educação e no ensino/aprendizagem, há tempos sofre para legitimar sua necessidade de existência e modificar a comum prática de "depósito de livros". Por isso, falar sobre as mazelas da Biblioteca Escolar nos permite falar também do profissional Bibliotecário, que tem nesta um campo de trabalho que funciona em pequena proporção, e que quando funciona, pode haver controvérsias, pois é escassa a presença deste profissional no comando das atividades funcionais deste espaço.

Recentemente, dentre os conjuntos de leis que permeiam o campo das Bibliotecas, livros e leitura, tem-se a lei 12.244/10 que universaliza a criação de Bibliotecas Escolares até 2020 , e que inclui em seu art. $3^{\circ}$ a exigência de que seja respeitada a profissão de Bibliotecário.

Neste sentido, esta pesquisa propôs discorrer sobre a questão da competência profissional do Bibliotecário Escolar, a fim de evidenciar sua importância neste local, incluindo como parte reflexiva a referida lei, sua relevância, importância e o que ela pode representar para a profissão.

Procurou-se entender se as competências profissionais desenvolvidas tipicamente por um Bibliotecário Escolar, fazem jus ao serem requisitadas e promulgadas por meio de um artigo específico do conteúdo de uma lei da qual prevê a universalização de Bibliotecas, já que por fatores históricos, sociais, culturais e políticos há tempos se prevalece com a falta de Bibliotecários nas maiorias das escolas, pois o problema maior é justamente não ter Bibliotecas.

Partindo daí, indaga-se, qual a visão e o pensamento que os profissionais das Bibliotecas Escolares possuem sobre a referida Lei e também sobre as competências profissionais para atuar neste espaço educacional? Como objetivo geral considerou-se partir do aporte teórico sobre Bibliotecas e Bibliotecários e analisar as competências profissionais desenvolvidas pelo Bibliotecário Escolar com base na lei 12.244/10; como objetivos específicos a proposta foi descrever as competências profissionais pertinentes ao Bibliotecário Escolar; analisar as competências profissionais dos responsáveis por Bibliotecas Escolares na região de Londrina, PR; refletir quanto as competências profissionais do Bibliotecário Escolar considerando em especial a importância do art. 3ำ da lei $12.244 / 10$ para a profissão. 
Para tanto, a pesquisa contou com a aplicação de questionários em Bibliotecas de escolas da Zona Oeste e Central da cidade de Londrina, PR compostas por escolas da rede estadual, municipal e particular.

Desta forma, diante do contexto que muitas vezes é de abandono da Biblioteca Escolar e evidentemente do Bibliotecário, este tema provoca inquietação no que diz respeito à necessidade de analisar, para então ressaltar, a importância das habilidades, ações, práticas, técnicas, enfim, as competências profissionais que são pertinentes ao Bibliotecário Escolar e que tanto podem contribuir com a escola e professores.

\section{O CONCEITO DE COMPETÊNCIA}

Historicamente, até o fim da Idade Média o termo "competência" era expressão exclusiva da área jurídica (para julgamento de questões), sendo posteriormente utilizada na área empresarial para determinar a realização de certos trabalhos, além de ser utilizado no meio acadêmico (SILVA, 2005).

Este conceito utilizado pelo norte-americano David McClelland resultou em estudos entre os anos 60 e 70 que abordavam variáveis de competências utilizadas para identificar desempenho no trabalho independente de outros fatores.

Segundo Silva (2005) a qualificação é essencial para sobreviver no crescente mercado competitivo e também para o sucesso da organização. Dessa forma, a ideia de competência profissional isoladamente é um assunto que há tempos desperta discussões e reflexões, como por exemplo, nas áreas da sociologia, administração, gestão de pessoas, etc.

Para Meghnagi (1999), no decorrer dos anos e de forma geral, as mudanças sociais, econômicas e culturais, interferiram nas profissões preexistentes. O autor comenta que as ideias das competências não são predefinidas nem adquiridas em formações, devido a estas mudanças e contextos, ou seja, torna as competências algo que o próprio indivíduo precisa moldar.

Quanto a relação da competência e a qualificação, segundo Farias e Cunha (2009, p. 30) os pontos convergentes e divergentes destes dois termos requerem 0 estabelecimento de conjunto de mediações "[...] já que são conceitos polissêmicos, recheados de significados sociais e políticos, que se atualizam em conjunturas históricas distintas." 
Nacionalmente, temos o surgimento por intermédio de um acordo firmado entre o Brasil e a ONU (Organização das Nações Unidas) em 1977, a criação da CBO (Classificação Brasileira de Ocupações) que teve como base a Classificação Internacional Uniforme de Ocupações (ClUO-1968), para classificar e oficializar as ocupações brasileiras.

Entende-se que ocupação "[...] é a agregação de empregos ou situações de trabalho similares quanto às atividades realizadas [...]" e "[...] emprego ou situação de trabalho: definido como um conjunto de atividades desempenhadas por uma pessoa, com ou sem vínculo empregatício. Esta é a unidade estatística da CBO." (BRASIL, 2002, Não paginado).

Assim, de acordo com a CBO (Classificação Brasileira de ocupações) o conceito de Competência possui duas dimensões: uma se refere ao nível de competência e outra ao domínio/especialização. O nível de competência é a função d complexidade, "[...] amplitude e responsabilidade das atividades desenvolvidas no emprego ou outro tipo de relação de trabalho." (BRASIL, 2002, Não paginado). O domínio ou especialização da competência está relacionado aos elementos do contexto do trabalho como área de conhecimento, função, atividade econômica, processo produtivo, equipamentos, bens produzidos que identificarão o tipo de profissão ou ocupação.

Contudo, compreende-se neste contexto da pesquisa que Competência consiste no saber, no conjunto de conhecimentos, habilidades e atitudes. $E$ as habilidades especificamente, no saber fazer, isto é, na ação de pôr em prática os conhecimentos dos quais se tornam experiências e capacidades adquiridas.

Assim, independente de teorias de modelos e termos abrangentes ou substitutivos em torno da questão de competência profissional, o fato é que a competência possui intima relação com a forma de exercer a profissão. É por meio dela que se é possível mostrar qual a capacidade que se tem e na área que si diz ser competente. Certo de que, ao evidenciar tais competências o profissional assegura um espaço de trabalho, sua profissão e o seu próprio fazer. Compreende-se, então, que ser competente não se restringe a algo fixo e definitivo, mesmo que seja dentro de uma área especifica, mais sim num movimento, numa flexibilidade da qual a área pode exigir no mercado de trabalho, e em alguns casos pode haver também a necessidade de desenvolver competência em várias áreas para melhor atender as possibilidades de emprego. Entretanto, isto levanta outra problemática (não abordada neste momento), pois remete a individualidade, e exige 
do profissional interesse e aptidão em se adaptar a situações e competências que podem fugir aos seus anseios e sucessos profissionais. Sobretudo quando se adentra em áreas de formações distintas ao qual se pertença.

\section{O BIBLIOTECÁRIO ESCOLAR E SUAS COMPETÊNCIAS PROFISSIONAIS}

A necessidade de abordar a questão de competência profissional do Bibliotecário consiste em algo que defina e justifique suas competências como parte essencial para o bom funcionamento das Bibliotecas Escolares.

Neste sentido, Tavares (1973, p. 27) afirma que "[...] graças ao trabalho eficiente do Bibliotecário é que a Biblioteca pode existir, da sua ação, do seu conhecimento, depende a Biblioteca para ser dotada e estar preparada para atender as necessidades do aluno." Entretanto no âmbito da Biblioteca Escolar, a falta de um profissional qualificado e munido de suas competências, é algo comum, já que este seria um, dentre vários motivos que assombram a realidade das Bibliotecas Escolares. Como comenta Fragoso (2002, p. 128): "É verdade que a maior parte das Bibliotecas Escolares brasileiras não conta com o Bibliotecário à sua frente."

No entanto, mesmo diante deste problema estrutural que atinge o campo de trabalho do Bibliotecário nas escolas, não é admissível que a Biblioteca Escolar continue em sua maioria sendo desprovida dos cuidados de um profissional que seja competente nesta área. Pois, ocorre que "[...] grande parte das Bibliotecas escolares e públicas, que apesar de se constituírem em um mercado informacional tradicional, correspondem também a espaços não ocupados [...]", ou seja, pertence ao mesmo tempo ao primeiro grupo e ao segundo - mercado informacional existente não ocupado (VALENTIM, 2000 apud RUSSO, 2010, p. 127).

Dessa forma, tal dualidade existente, exalta a necessidade de consolidação desta área, devido aos benefícios que um profissional capacitado pode oferecer para as Bibliotecas Escolares, assim como para o processo de formação e própria estrutura da escola. Por isso, ser Bibliotecário não se resume em desempenhar uma determinada carga horária contratada, no qual se realize empréstimos e devoluções de livros, pois a questão da competência nem sempre pode ser regidas por regras, pois ela pode variar dependendo do contexto, seguindo seu curso normal dos acontecimentos do cotidiano. E 
o Bibliotecário fazendo uso das suas competências deve saber orientar alunos em etapas de formação diferente e em contextos diferentes.

Para afirmar as competências do Bibliotecário, surge a necessidade de elencar as habilidades (ações de suas competências) pertinentes a Biblioteca escolar, bem como amostras reais de como elas são aplicadas e vivenciadas, pois como explica Almeida Júnior (2006), há o agravante do desconhecimento das funções do fazer Bibliotecário. Sendo que o Bibliotecário ideal seria aquele em procura conhecer e questionar sua área e que sabe que o usuário é seu fim e que a informação que será tratada e disponibilizada será essencial para a formação de cidadãos. "O Bibliotecário Escolar é aquele que reconhece sua profissão como importante e necessária para a sociedade e se reconhece como um agente de transformação." (ALMEIDA JÚNIOR, 2006, p. 53-54).

De acordo com Côrte e Bandeira (2011, p. 15) o Bibliotecário Escolar necessita ter competências como:

$\checkmark \quad$ Possuir curso de biblioteconomia, conforme a lei no 4084/62;

$\checkmark$ Ser um investigador permanente; Possuir atitudes gerenciais proativas;

$\checkmark \quad$ Possuir espírito crítico e bom senso;

$\checkmark \quad$ Ser participativo, flexível, inovador, criativo;

$\checkmark \quad$ Facilitar a interação entre os membros da comunidade escolar;

$\checkmark \quad$ Possuir capacidade gerencial e administrativa;

$\checkmark$ Possuir capacidade de comunicação e relacionamento interpessoal;

$\checkmark \quad$ Saber que é a informação é imprescindível à formação do aluno;

$\checkmark$ Dominar as modernas tecnologias da informação;

$\checkmark \quad$ Estar em constante questionamento;

$\checkmark \quad$ Estar atualizado na sua área de atuação;

$\checkmark \quad$ Ter consciência de que o usuário é seu fim último;

$\checkmark \quad$ Saber que a informação é imprescindível à formação do cidadão;

$\checkmark$ Reconhecer sua profissão como importante e necessária para a sociedade;

$\checkmark$ Reconhecer-se como um agente de transformação social e

$\checkmark \quad$ Ser um leitor crítico, que distingue, no momento da seleção e da indicação de livro, a literatura infantil e juvenil que é de qualidade. 
Em 1996 foi elaborado um estudo pela SLA (Special Libraries Association) organização de bibliotecários especializados, referente às "[...] competências e as habilidades que os bibliotecários devem apresentar para trabalhar no momento atual - em que as transformações sociais e tecnológicas acontecem muito rapidamente - e no futuro." Assim, segundo o texto "Competências para os Bibliotecário do século 21" adaptado do relatório "Competencies for Special Librarians of the 21st Century" pode-se dizer que o conhecimento de recursos informacionais tanto impresso quanto eletrônicos e a administração de serviços de informação são as competências exigidas ao profissional do futuro. Partindo desse estudo identificaram-se determinadas competências que o Bibliotecário necessita ter, levando-se em conta duas categorias de competências que podem ser:

Quanto às competências profissionais, tem-se que:

$\checkmark$ Conhecimento especializado do conteúdo dos recursos de informação existentes na Biblioteca, incluindo a habilidade de avaliá-los criticamente e filtrá-los;

$\checkmark \quad$ Conhecimento especializado do(s) assunto(s) de interesse da organização onde funciona a Biblioteca ou centro de informação;

$\checkmark \quad$ Habilidade de desenvolver e administrar serviços de informação convenientes, acessíveis e de baixo custo que estejam alinhados com as orientações estratégicas da organização;

$\checkmark \quad$ Habilidade para oferecer excelente treinamento e apoio aos usuários da Biblioteca e dos serviços de informação existentes na organização;

$\checkmark \quad$ Habilidade para levantar necessidades de informação e desenvolver e vender serviços e produtos de informação com alto valor agregado, atendendo as necessidades identificadas;

Saber usar a tecnologia da informação para adquirir, organizar e disseminar informação;

Saber usar abordagens apropriadas de negócios e de marketing para comunicar a importância dos serviços de informação para a cúpula administrativa da organização;

$\checkmark \quad$ Saber desenvolver produtos de informação específicos para uso interno ou externo à organização ou para clientes individuais;

$\checkmark \quad$ Saber avaliar os resultados do uso da informação e conduzir pesquisa focada para a solução de problemas de gestão de informação; 
$\checkmark \quad$ Saber aprimorar continuamente os serviços de informação em resposta às mudanças nas necessidades;

$\checkmark \quad$ Ser um membro efetivo da alta gerência e atuar como consultor em questões de informação dentro da organização. (COMPETÊNCIAS..., 1996, Não paginado).

E quanto às competências pessoais, tem-se que:

$\checkmark$ Comprometer-se com a excelência no desempenho de suas atividades profissionais;

$\checkmark \quad$ Buscar desafios e visualizar novas oportunidades dentro e fora da Biblioteca;

$\checkmark \quad$ Ter uma visão geral e abrangente da organização;

$\checkmark \quad$ Buscar parcerias e alianças;

$\checkmark \quad$ Criar um ambiente de respeito mútuo e confiança;

$\checkmark \quad$ Ter habilidades efetivas de comunicação;

$\checkmark \quad$ Trabalhar bem em equipe;

$\checkmark \quad$ Exercer liderança;

$\checkmark \quad$ Planejar, priorizar e focar os pontos críticos;

$\checkmark$ Comprometer-se a aprender durante toda a vida e a planejar a carreira pessoal;

$\checkmark \quad$ Ter habilidade pessoal para negócios e saber criar novas oportunidades;

$\checkmark \quad$ Reconhecer o valor das redes de contato pessoal e profissional;

$\checkmark$ Reconhecer o valor da solidariedade;

$\checkmark$ Ser flexível e otimista em tempo de mudanças constantes; (COMPETÊNCIAS..., 1996, Não paginado).

Outra vertente, segundo Farias e Cunha (2009) partindo das dimensões de competência designadas pela Classificação Brasileira de Ocupações, que fora citada anteriormente complementa dizendo que além de dimensões técnicas o Bibliotecário Escolar pode se enquadrar em dimensões técnicas, políticas, estéticas e éticas, pois a dimensão técnica se refere a construir conteúdos de acordo com a necessidade dos usuários a dimensão estética se refere às habilidades criativas e subjetivas que todo profissional deve ter, a dimensão política permite que o profissional visualize sua 
participação e efetive uma construção de entendimento de direitos e deveres e a dimensão ética orienta para a realização do bem coletivo (FARIAS; CUNHA, 2009, p.3233).

A partir da CBO (BRASIL, 2002), pode-se citar as especificações dadas pelo "Relatório Tabela de Atividades" que este órgão determina para o Bibliotecário (Profissional da Informação), embora não diretamente, é claro, para a atuação em Bibliotecas escolares, mais que servem de parâmetros para o profissional de uma forma ampla. Assim, destacam-se os seguintes tópicos:

$\checkmark$ Disponibilizar informação em qualquer suporte;

$\checkmark$ Gerenciar unidades, redes e sistemas de informação;

$\checkmark$ Tratar tecnicamente recursos informacionais;

$\checkmark$ Desenvolver recursos informacionais;

$\checkmark$ Disseminar informação;

$\checkmark$ Desenvolver estudos e pesquisas;

$\checkmark$ Prestar serviços de assessoria e consulta'

$\checkmark$ Realizar difusão cultural;

$\checkmark$ Desenvolver ações educativas e

$\checkmark$ Demonstrar competências pessoais.

De acordo com as autoras Farias e Cunha (2009), o Bibliotecário deve ser reflexivo, ter capacidade de avaliação, pois refletem na tomada de decisão que influenciam nos objetivos educacionais e na ética da profissão.

Colocar em prática as habilidades que um Bibliotecário Escolar deve ter é de responsabilidade própria, pois abrange suas competências profissionais. Já a precariedade da Biblioteca escolar, comum em muitos casos, não é um problema individual do profissional, mais sim da falta de compromisso existente neste setor, que em desuso, acaba por distanciar as possibilidades de atuação do profissional.

Com a lei 12.244/10 que universaliza a criação de Bibliotecas, não é discrepante dizer que envolve diretamente o profissional e suas competências, já que de pouco reconhecido, passa a ser mencionado como um dos itens indispensáveis para a aplicação total da lei. A propósito disso, cabe-nos daqui para frente refletir sobre esta lei que tanto pode nos dar respaldo enquanto profissional. 


\section{A LEI 12.244/10 E SUAS REPERCUSSÕES}

Pode-se entender que o termo lei é um conjunto de normas jurídicas, ou seja, é um documento normativo. Elas surgem para organizar as mais variadas situações que se encontram em conflito na sociedade, logo procuram estabelecer possibilidades de proteção ao indivíduo e visam garantir que seus direitos posam ser respeitados.

Nesse sentido, tanto a inexistência de Bibliotecas escolares, como a falta de Bibliotecários atuando nestes ambientes, gera há tempos, conflitos que perpassam pela deficiência causada na formação do aluno (principalmente no hábito da leitura), pois o suporte Biblioteca deixa a desejar enquanto aparato funcional, como também pelo fato de que os Bibliotecários são substituídos por outros profissionais que assumem as Bibliotecas das escolas.

Dessa forma, tal conflito e suas reivindicações, resultaram por intermédio da Lei de universalização das Bibliotecas nas escolas, uma medida que representa de forma significativa os anseios de uma camada da sociedade que requer melhorias.

É importante saber que o processo que envolve a aprovação da lei 12.244/10 engloba situações prévias que demandam tempo e ação de tramitação no Congresso até chegar asanção, promulgação e publicação no Diário Oficial da União. Dessa forma, vale recapitular que:

\footnotetext{
Originalmente, o PL surgiu sob a autoria da ex-deputada federal Ester Grossi (PT/RS) ainda na década de 1990. Posteriormente, tramitou sob a responsabilidade da deputada Federal Vanessa Grazziotin (PCdoB/AM). No entanto, foi sob a autoria do deputado federal Lobbe Neto (PSDB/SP) e com as contribuições do CFB, que o PL seguiu seu curso na Câmara Federal e foi enviado à Comissão de Educação do Senado sob a relatoria do senador Cristovam Buarque. (BRASIL, 2010, Não paginado).
}

Assim, após a proposta feita no ano de 2000 pela então deputada Ester Grossi, foi apenas em 2003 que reapresentada, tornou-se Projeto de Lei da Câmara no 324/09, que também pode ser identificado pelo ํㅡ 1831/03, referente a casa de origem do deputado Lobbe Neto, no qual dispõe sobre a universalização das bibliotecas escolares nas instituições de ensino do país.

Já o projeto de lei oㅡ 3230/04 apresentado em 24/03/2004 pela Deputada Federal Vanessa Grazziotin (PCdoB/AM) em virtude do projeto 1831/03 foi arquivada em 13/01/2010. 
Dessa maneira, o projeto reapresentado por Lobbe Neto começou a tramitar no dia 21/12/2009, tendo a partir de 22/12/2009, cinco dias úteis para receber emendas, conforme informa o Portal de Atividade Legislativa do Senado.

Após o prazo, e a não existência de emendas oferecidas ao projeto, foi designado como relator, o Senador Cristovam Buarque, no qual devolveu o projeto de lei em 06/04/2012 e determinou-o como "Relatório favorável, estando em condições de ser incluído em pauta." (BRASIL, SENADO, 2009, Não paginado).

Entretanto, somente no dia 13 de abril de 2010 que este projeto de lei da câmara foi aprovado pela Comissão de Educação do Senado em caráter terminativo, obtendo 14 votos favoráveis. A partir de então, houve um novo caminho a ser percorrido, pois como foi dito pela presidente Nêmora Rodrigues (2011, Não paginado) "A grande campanha nacional agora é pela sanção do presidente Lula."

Depois da aprovação, levou-se pouco mais de dois meses o tramite que transformou e sancionou em 24/05/2012 o projeto em norma jurídica - Lei 12.244/10.

Deste modo, como a formação básica do cidadão é de responsabilidade governamental de um país, logo variáveis que contribuem com este processo são atribuídos de forma a oferecer subsídios para uma aplicação que alcance resultados. Diante disso, pode-se dizer que a referida lei é mais uma favorável aos interesses da Educação.

Para Côrte e Bandeira (2011, p. 6) o questionamento sobre uma pergunta do tipo "porque" e "para que" é importante a existência da Biblioteca Escolar, pode ser baseada na formalização da lei 12.244/10, pois integra o cenário desta importância e pode ser fundamentada a partir de duas premissas.

Contudo, este avanço não se restringe ao conjunto de regras impostas ao ensino, mais principalmente se mostra como um avanço para a área da Biblioteconomia e do Bibliotecário, que como exposto, precisa ganhar maior espaço de atuação dentro das Bibliotecas escolares.

Quanto a redação da lei, esta pode inferir dúvidas quanto ao seu cumprimento, em relaçãoa qualidade deste cumprimento no que tange ao acervo, porém é inegável a positividade que ela transmite quanto a aceitação de mais um campo de trabalho para o Bibliotecário.No entanto, é preciso ressaltar, que segundo a Agência Brasil (2010) um estudo feito pelo movimento "Todos pela Educação", identificou que "[...] hoje há um total 
de 21,6 mil profissionais habilitados, enquanto o país conta com aproximadamente 200 mil escolas de educação básica."

Com o surgimento da lei de universalização das Bibliotecas nas escolas, incluindo o ponto em que se acentua que a adequação deve ocorrer também a partir da participação da presença do profissional, ou seja, do Bibliotecário que regulamentado é o responsável por efetivar os serviços necessários para a adequação da lei e que prevê o prazo de dez anos para ser de fato implantada.

Visto como um progresso, a lei trouxe consigo muitas repercussões, e na abordagem deste trabalho o ponto culminante para a reflexão e desenrolar dos objetivos da pesquisa está no seguinte artigo:

Art. $3^{\circ}$ Os sistemas de ensino do País deverão desenvolver esforços progressivos para que a universalização das Bibliotecas escolares, nos termos previstos nesta Lei, seja efetivada num prazo máximo de dez anos, respeitada a profissão de Bibliotecário, disciplinada pelas Leis $n^{\text {os }} 4.084$, de 30 de junho de 1962, e 9.674, de 25 de junho de 1998. (BRASIL, 2010, Não paginado).

Este artigo assegura o Bibliotecário como parte indispensável para o objetivo de universalizar a criação de Bibliotecas nas escolas, fornecendo o reconhecimento pelo seu trabalho, que como foi refletido, antes de seu surgimento oficial, muitos foram os que se apoderaram da função por motivos que mais tarde se ampliaram e restringiram-se aqueles realmente com formação. Mais que, no entanto, não impediu que a Biblioteca das escolas perante seu fator histórico de falta de reconhecimento, fosse ao longo dos anos, um campo com poucos profissionais atuantes.

Divulgado pelo jornalista Alexandre Pôrto, da Rádio Câmara, o censo do Ministério da Educação de 2010 divulgou que "[...] 66\% das escolas de ensino fundamental do país não tinham Bibliotecas. No caso do ensino médio, faltavam Bibliotecas em $28 \%$ dos estabelecimentos." Ainda de acordo com Rádio Câmara, a presidente do Sindicato dos Professores do Ensino oficial de São Paulo, Maria Izabel Azevedo Noronha, "[...] ela elogia o fato de a lei prever, além da implantação das Bibliotecas, o respeito à regulamentação da profissão de bibliotecário." Já na Agência do Rádio, a repórter Silaine Bohry, relata que sobre o bibliotecário, o senador Cristovam Buarque do PDT enfatiza que "A atuação desse profissional permite a disseminação precisa de informações e conhecimentos para promover o desenvolvimento cultural e social do País." e acrescenta 
ainda que: "[...] sem uma bibliotecária ou um bibliotecário, que organiza os livros, que se preocupa em buscar mais livros, não tem como ter uma boa biblioteca." (AGÊNCIA DO RÁDIO, 2012, Não paginado).

A oficialização da lei 12.244/10 além de repercutir entre os profissionais da área e da educação possibilitou também um avanço no que se refere ao ensino de Biblioteconomia, pois como afirma Nêmora Rodrigues, a grande demanda de profissionais que seriam necessários para atender a aplicação da lei, fez com que o CFB/CRB firmasse convênio a Universidade Aberta do Brasil (UAB CAPES/MEC) "Para oferta do curso de Biblioteconomia na modalidade a distância, a fim de possibilitar que especialmente os alunos residentes fora das grandes cidades onde são oferecidos os cursos presenciais possam vir a ingressar." (BRASIL, 2011, Não paginado).

Ocorre que entre os esforços necessários para que aconteça a concretização desta lei, está na problemática das futuras Bibliotecas que terão que ser construídas, pois de acordo com a Agência Brasil (2010, Não paginado), tanto os municípios quanto para os estados "O maior desafio está nos estabelecimentos do ensino fundamental: será necessário construir 25 Bibliotecas por dia até 2020, prazo limite para adequação à medida."

Esse dado foi levantado e a partir do Censo da Educação Básica de 2008, realizado pelo movimento Todos pela Educação, como relata Luís Norberto: "Essa dificuldade é decorrente da falta de visão do Brasil sobre a importância da Biblioteca. No mundo todo, as Bibliotecas são doadas por mantenedores que têm uma alegria imensa de poder doar um acervo." (AGÊNCIA BRASIL, 2010, Não paginado).

O déficit de Bibliotecas no ensino fundamental é de 93 mil. Desse total, 89,7 mil são escolas públicas e 3,9 mil, estabelecimentos privados de ensino. Na educação infantil, apenas $30 \%$ dos colégios têm acervo e será necessário criar 21 Bibliotecas por dia para cumprir o que determina a nova lei. A melhor situação é a do ensino médio, etapa em que o número de escolas sem Biblioteca é de 3.471. (AGÊNCIA BRASIL, 2010, Não paginado).

De acordo com Ocimara Balmant (2013) do jornal Estado de São Paulo, em 72,5\% das escolas não há Bibliotecas, sendo que na rede pública apenas 27,5\% possuem Bibliotecas. Assim, "O Brasil precisa construir 130 mil bibliotecas até 2020 para cumprir a Lei 12.244 [...]", não devendo se esquecer de que: "Para que a biblioteca escolar cumpra seu papel pedagógico, deve-se levar em conta do espaço físico à qualificação dos 
funcionários, passando pela qualidade do acervo e pelas atividades agendadas no local." Dessa maneira, "[...] a justificativa mais comum para desrespeitar a lei é a falta de espaço físico, já que muitas das novas escolas são construídas em terrenos apertados." (BALMANT, 2013, Não paginado).

Nota-se que a enfatizada lei 12.244/10 ocasionou uma série de incitações acerca do Bibliotecário e da Biblioteca Escolar, e que mostra a preocupação da sociedade em mudar este quadro critico, do qual se encontra as Bibliotecas das escolas, bem como a importância de valorização do Bibliotecário e seu espaço de atuação, pois é preciso reivindicar melhorias, mais é preciso também saber acatar e tornar realidade as possibilidades que surgem para a concretização de algo tão esperado.

\section{RESULTADOS DA PESQUISA}

Para o desenvolvimento deste estudo, foram estabelecidas algumas diretrizes que possibilitaram alcançar o objetivo principal. $O$ tipo de pesquisa aplicado foi exploratória e descritiva e a natureza da pesquisa se caracterizou em abordagem qualitativa. Para delimitar o universo da pesquisa, utilizaram-se como fonte de informação, os dados que estão disponíveis no site da Secretaria da Educação do Estado do Paraná (referência ano de 2013). Assim, de acordo com esta fonte há na cidade de Londrina 73 escolas estaduais, 92 escolas municipais e 158 escolas particulares. Partindo destes dados, o universo da pesquisa resultou em 323 escolas. Contudo, ignorando quais destas escolas teriam ou não Bibliotecas e tendo em vista a abordagem qualitativa, foram selecionados como sujeitos de pesquisa, 25 Bibliotecas deste universo, adotando como critério de delimitação, as Bibliotecas das quais as escolas estivessem localizadas nas zonas oeste e centralda cidade de Londrina, independentemente de serem da rede municipal, estadual ou particular.

As 25 Bibliotecas foram selecionadas a partir de uma amostragem aleatória por sorteio. $O$ instrumento de coleta de dados utilizado foi o questionário que intencionalmente, conteve questões abertas e fechadas. Osquestionáriosforam enviados via e-mail e aplicado pessoalmente. Seguem-se os resultados obtidos.

Para iniciar a análise e interpretação dos dados, o instrumento de pesquisa foi ordenado a fim de agrupar os assuntos do questionário por temas, o que facilitou a identificação das questões que se relacionavam. 
Quadro 1 - Primeira Parte - Caracterização dos Respondentes

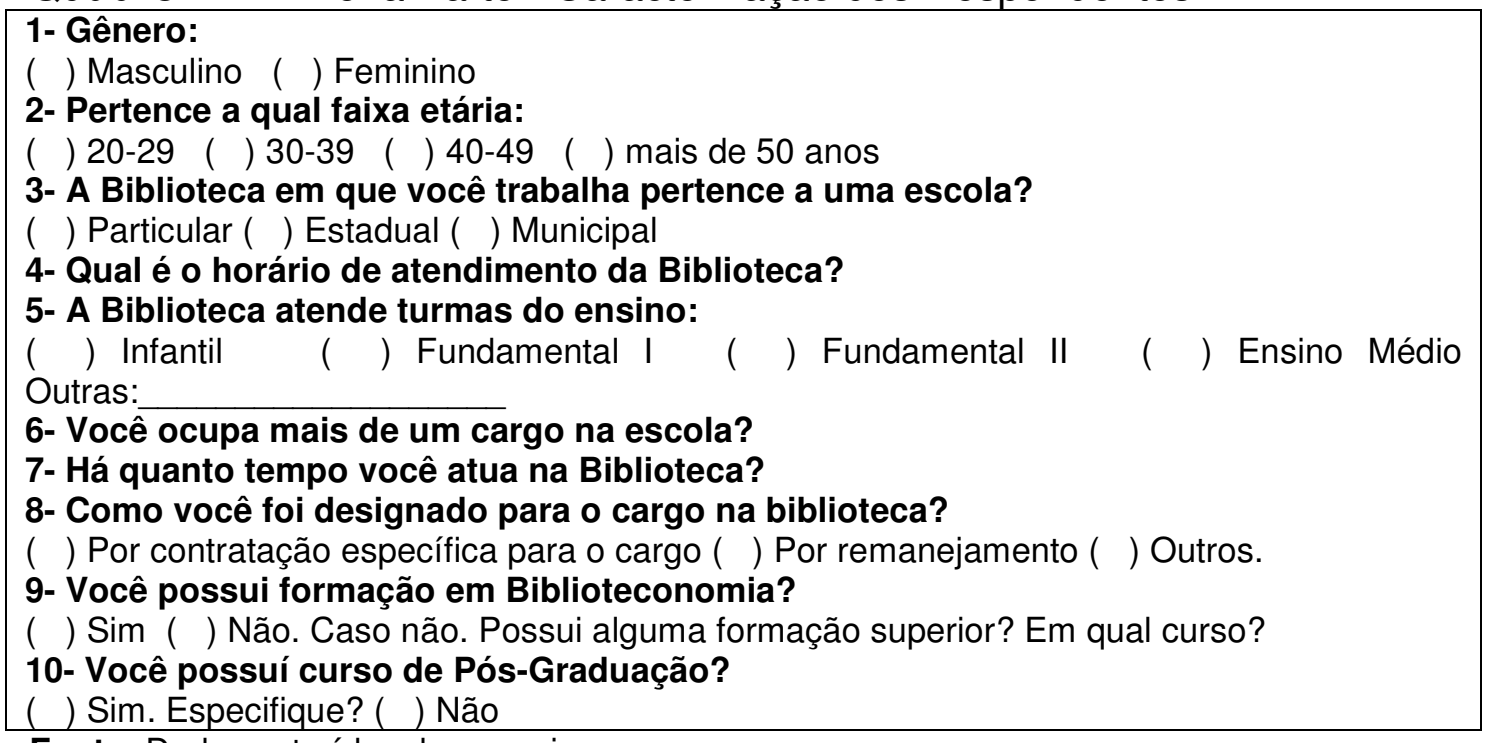

Fonte: Dados extraídos da pesquisa.

Dos 25 questionários distribuídos, foram recuperados 20, mais especificamente, 3 de Biblioteca de escola municipal, 8 de estadual e 9 de particular.

Nos itens arrolados no questionário acima, a caracterização dos respondentes serviu para identificar o perfil e a função dos profissionais atuantes nas Bibliotecas Escolares de Londrina. Por função, entende-se qual a ocupação, atribuição de cada participante da pesquisa, já que previamente era possível imaginar que não se encontraria apenas Bibliotecários atuando neste espaço.

Assim, verificou-se que os profissionais atuantes nas Bibliotecas escolares de Londrina, possuem formação superior em diversos cursos como: Tecnologia em processamentos de dados, História, Administração de empresa, Gestão em Recursos Humanos, Ciências Sociais, Pedagogia, Biblioteconomia e Normal Superior.

Vale mencionar, que no quesito formação, foi obtido com a pergunta (№ 9) "Você possui formação em Biblioteconomia"? a resposta como: "Sim. curso técnico oferecido pelo governo" (Respondentes S, formado em Pedagogia e atua na Rede Estadual de Ensino). Com isso, a participante se auto intitula um Bibliotecário, posto este, associado a ideia de que curso técnico é sinônimo de formação específica para o cargo, ou seja, evidencia o total desconhecimento quanto a necessidade de se ter graduação para ser chamado de Bibliotecário.

Quanto a essa realidade e a da própria Biblioteca escolar, não nos convém ficar admirados, pois, como explica Garcez (2007), a biblioteca no meio escolar é quase inexistente o que faz com que a percepção de seu público, tanto profissional quanto 
usuário, a vejam apenas como um lugar de livros e estantes que tem um funcionário que por vezes é chamado de forma errônea de bibliotecário. Constata-se, então que algumas das Bibliotecas que participaram desta pesquisa, não possuem profissionais com formação em Biblioteconomia, e analisando quanto aos cursos de aperfeiçoamento dos participantes da pesquisa, verificou-se que são cursos Latu Sensu como: Gestão Escolar, Gestão de Biblioteca Escolar, Estudos em Religião, Informação, Conhecimento e Sociedade, Administração Hospitalar e História Social.

A pluralidade destes cursos denota que num primeiro momento a realidade é de que nem todos os funcionários atuantes na Biblioteca possuem formação específica na área, e por sua vez, os cursos de aperfeiçoamento de forma geral também não condizem com a área da Biblioteca Escolar, mesmo tendo apresentado de acordo com os respondentes, a média de 36 anos de idade, sendo mínima de 20 e máxima de 50 anos. Já o tempo de atuação está na média de 9 anos, mínima de 1 e máxima de 25 anos na mesma função - setor da Biblioteca. É relevante dizer que das 20 Bibliotecas, somente 10 possuem Bibliotecário como responsável pelo setor, sendo que 9 são de escolas particulares e 1 estadual, o restante são 8 professores remanejados, sendo 7 do estado e um do município e por fim 2 entre município e estado, que não revelados, foi indicado apenas como por "outros motivos".

Quanto as turmas que são atendidas, constatou-se que as Bibliotecas das escolas de Londrina funcionam em horário integral, salvo exceções de algumas que não possuem horário definido ou só atendem em uma parte do dia, deixando assim, de atender em algum momento, determinados grupos de alunos. O público está dividido entre ensino infantil, fundamental, médio, curso técnico e pré-vestibular, e também pais, funcionários e a comunidade. Contudo, não se pode enquadrar a abertura como ruim, pois a maioria atende em horário integral, independente de ser Bibliotecário ou não, porém, de acordo com "[...] os resultados da edição 2012 da pesquisa Retratos do Brasil, que mostrou que, entre os 5 e 17 anos, as bibliotecas escolares estão à frente de qualquer outra forma de acesso ao livro (64\%)." (BALMANT, 2013, Não paginado).

Ressaltando, que na rede municipal há casos de funcionários (não Bibliotecários), que atendem a Biblioteca e desempenham o cargo de professor na mesma escola. $\mathrm{Na}$ rede particular, identificou um Bibliotecário que também ministra aulas de informática e de Literatura, e outro, que desempenha demais serviços administrativos. Já nas da rede estadual, são funcionários exclusivos para o setor da Biblioteca. 
Vale relatar que segundo Balmant (2013, Não paginado) as instituições de ensino infantil são as mais prejudicadas por não conter Bibliotecas, pois "[...] enquanto $82 \%$ das escolas de ensino profissional e $52 \%$ das de ensino médio construídas após 2008 possuem biblioteca, apenas $10 \%$ das de ensino infantil têm o espaço." Porém, nesta pesquisa a partir dos 20 questionários recebidos, isso significa a existência igualmente de Bibliotecas, sendo que neste universo a maioria abrange o ensino infantil, mais não unicamente, e sim, juntamente com outras turmas, o que ressalta a dúvida da existência de Bibliotecas caso não houvesse os demais ensinos como fundamental, médio, técnico e vestibular.

Quadro 2 - Segunda Parte - Competências Profissionais do Bibliotecário Escolar 14 - Quais destas atividades abaixo você julga ser de sua competência profissional? (Pode assinalar mais de uma opção)

\begin{tabular}{|l|l|l|}
\hline ATIVIDADES & SIM & NÃO \\
\hline Analisa a necessidade informacional da comunidade escolar? & & \\
\hline $\begin{array}{l}\text { Elabora políticas de desenvolvimento de serviços para a rotina da } \\
\text { Biblioteca? }\end{array}$ & & \\
\hline Elabora política de desenvolvimento de coleções? & & \\
\hline $\begin{array}{l}\text { Elabora política de marketing para a Biblioteca? } \\
\text { catalogação, classificação, indexação, etc. }\end{array}$ & & \\
\hline Oferece serviços de referência? & & \\
\hline Oferece serviço de Disseminação Seletiva da Informação (DSI)? & & \\
\hline Realiza atividades de fomento à leitura? & & \\
\hline $\begin{array}{l}\text { Promove ação cultural, como: Hora do Conto, roda de leitura, comemoração } \\
\text { de efemérides, etc.? }\end{array}$ & & \\
\hline Participa de reuniões pedagógicas? & & \\
\hline Administra recursos orçamentários? & & \\
\hline Realiza procedimentos de conservação e preservação do acervo? & & \\
\hline Realiza relatórios das atividades & & \\
\hline Realiza serviços de atendimento ao usuário? & & \\
\hline Utiliza tecnologias da informação para os serviços da biblioteca? & & \\
\hline
\end{tabular}




\begin{tabular}{|c|c|c|}
\hline \multicolumn{3}{|c|}{$\begin{array}{l}\text { 15- Quais destas atividades abaixo você de fato realiza, ou seja, quais fazem parte da } \\
\text { rotina de serviços da biblioteca em que trabalha? (Pode assinalar mais de uma opção) }\end{array}$} \\
\hline ATIVIDADES & SIM & NÃO \\
\hline Analisa a necessidade informacional da comunidade escolar? & & \\
\hline Elabora políticas de desenvolvimento de serviços para a rotina da Biblioteca? & & \\
\hline Elabora política de desenvolvimento de coleções? & & \\
\hline Elabora política de marketing para a Biblioteca? & & \\
\hline $\begin{array}{l}\text { Realiza serviços técnicos nos materiais da Biblioteca como, por exemplo, } \\
\text { catalogação, classificação, indexação, etc.? }\end{array}$ & & \\
\hline Oferece serviços de referência? & & \\
\hline Oferece serviço de Disseminação Seletiva da Informação (DSI)? & & \\
\hline Realiza atividades de fomento à leitura? & & \\
\hline $\begin{array}{l}\text { Promove ação cultural, como: Hora do Conto, roda de leitura, comemoração de } \\
\text { efemérides, etc.? }\end{array}$ & & \\
\hline Participa de reuniões pedagógicas? & & \\
\hline Administra recursos orçamentários? & & \\
\hline Realiza procedimentos de conservação e preservação do acervo? & & \\
\hline Realiza relatórios das atividades? & & \\
\hline Realiza serviços de atendimento ao usuário? & & \\
\hline Utiliza tecnologias da informação para os serviços da biblioteca? & & \\
\hline $\begin{array}{l}\text { 16- Com base nas respostas assinaladas como "Sim" na questão anterior, } \\
\text { modo sucinto como ocorrem na prática às atividades que são desenvolvid } \\
\text { especificamente com os alunos no dia-a-dia da Biblioteca? (Se desejar poc } \\
\text { outras atividades que não estejam no quadro) } \\
\text { 17- Caso não seja Bibliotecário, explique como são feitos os serviços técn } \\
\text { pertinentes às práticas de um profissional Bibliotecário. Como por exempl } \\
\text { catalogação, indexação e classificação. }\end{array}$ & $\begin{array}{l}\text { descr } \\
\text { e des } \\
\text { e des } \\
\text {, }\end{array}$ & $\begin{array}{l}\text { eva de } \\
\text { crever }\end{array}$ \\
\hline
\end{tabular}




\begin{tabular}{|l|l|l|}
\hline $\begin{array}{l}\text { 18- Quais características abaixo você considera importante para sua atuação na } \\
\text { Biblioteca? (Pode marcar mais de uma opção) }\end{array}$ \\
\hline \multicolumn{1}{|c|}{ Sim } & Não \\
\hline Manter-se atualizado & & \\
\hline Trabalho em equipe & & \\
\hline Criatividade & & \\
\hline Ética & & \\
\hline Iniciativa & & \\
\hline Senso de Organização & \\
\hline Liderança & & \\
\hline Flexibilidade & & \\
\hline $\begin{array}{l}\text { 19- Caso não seja Bibliotecário, você considera importante ter a presença deste } \\
\text { profissional para atuar na Biblioteca? } \\
\text { ( ) Sim. Por quê? } \\
\text { ( ) Não. Por quê? }\end{array}$
\end{tabular}

Fonte: Dados extraídos da pesquisa.

O segundo ponto na divisão se refere as competências do profissional Bibliotecário Escolar. De acordo com o posicionamento tomado no aporte teórico desta pesquisa, compreende-se que competência profissional consiste em um conjunto de conhecimentos, habilidades e atitudes, isto é, o termo competência está intimamente ligada com o "saber" e com a apropriação de conhecimentos. Enquanto, habilidades e atitudes se completam, isto é, entende-se como o "saber fazer", é o "colocar em prática o saber", ou ainda, por quaisquer outras similaridades que se relacionam com a ação contraída pela experiência dos conhecimentos. O Bibliotecário Escolar se enquadra em funções relativas às habilidades de saber fazer e saber aplicar, e que giram entre as esferas educativas, culturais, técnicas e administrativas, pois estas dentre outras concernentes, fazem parte do cotidiano da rotina de uma Biblioteca escolar.

A partir da questão (№ 19) - "Caso não seja Bibliotecário, você considera importante ter a presença deste profissional para atuar na Biblioteca?" obteve-se 18 respostas em concordância da necessidade de haver um profissional adequado na Biblioteca.

Deste modo, vale exemplificar com falas dos respondentes que não são formados na área, e que em suma responderam sim a questão, justificando que o Bibliotecário: 
"Por ser o profissional capacitado nesta área o qual poderá oferecer mais suporte às atividades da biblioteca, principalmente maior aprendizagem dos alunos". (Respondentes T, formado em Administração de Empresa, atua na Rede Estadual de Ensino);

$\checkmark$ "[...] Um bibliotecário estuda 4 anos, faz especialização deste modo sabe como atuar, diferente de outro profissional, que trabalha mas muitas vezes no improviso". (Respondentes J, formado em História, atua na Rede Municipal de Ensino).

Não obstante, houve respondentes que responderam contrariamente aos discriminados acima, dizendo que não consideram importante a presença deste profissional, pois estes "não desenvolvem o trabalho de fomentação a leitura e pelo o que acompanho é bastante falho nas escolas de ensino fundamental II em diante. Feedback que recebo dos alunos que passaram por aqui." (Respondentes $K$, formado em Curso Normal Superior, atua na Rede Estadual de Ensino). Esta generalização presumida pode ser contestada quando se identifica profissionais Bibliotecários fazendo a diferença em seus postos de trabalhos, o que nos permite replicar e argumentar.

Ainda de acordo com a questão sobre a importância de ter um Bibliotecário atuando nas Bibliotecas escolares, outro participante que não considera isto importante, argumentou que "se tratando de Escolas Publicas Estaduais o trabalho bem como as atividades podem ser realizados por um funcionário com o curso técnico da área". (Respondentes R, formado em Gestão de Recursos Humanos, atua na Rede Estadual de Ensino).

Neste ponto, surge uma inquietude quanto a esta colocação acima, pois na fala: "se tratando de Escolas Publicas Estaduais [...]" não fica claro se significa que as atividades nestes âmbitos, podem ser feitas a qualquer modo, ou resumidamente com a ajuda do curso técnico, já que são públicas, e por isso levanta a hipótese do descaso pela falta de possíveis recursos que estas Bibliotecas possam ter, sugerindo então, a falta de necessidade de um profissional graduado para este setor, ou ainda simplesmente, comprova o já esperado - a indiferença pelas competências profissionais dos Bibliotecários.

Estas visões apresentadas nos relatos anteriores, embora embaraçante, não se configura como uma surpresa, pois no histórico da Biblioteconomia, reforçando a partir de Salgado e Becker (1998, p. 1) "A formação bibliotecária tem por base a erudição e a técnica [...]", no qual receios sobre isso, já foram e ainda são, expostos nas literaturas da 
área, visto que "A literatura da década de 70 já alertava a problemática da falta de divulgação da profissão [...]", um dos motivos que resultam neste estigma (SALGADO; BECKER 1998, p. 2).

Entretanto, se por um lado, para alguns profissionais Bibliotecários o excesso de preocupações com técnicas pode representar fatos isolados, por outro, constata-se indesejavelmente, que o perfil do profissional está atrelado a uma generalização, da qual sem exceção faz com que na visão de certos profissionais distintos que atuam em Bibliotecas, ocorra como uma verdade concreta. Contudo, não apenas as ementas dos cursos foram se alterando, isto é, valorizando mais as temáticas de humanas, como o próprio Bibliotecário conhecem esta deficiência e também a necessidade de se auto rever, pois de forma ampla, pode se dizer, que as transformações sociais, econômicas e culturais impõe buscaratualização profissional.

Agora, especificamente sobre as técnicas biblioteconômicas, quando perguntado (№ 17): "Caso não seja Bibliotecário, explique como são feitos os serviços técnicos pertinentes às práticas de um profissional Bibliotecário. Como por exemplo, catalogação, indexação e classificação", obtiveram-se respostas taxativas como: "Não sou profissional com curso superior, mais tenho curso técnico e realizo normalmente todas estas atividades" (Respondente R, formado em Gestão de Recursos Humanos, atua na Rede Estadual de Ensino).Seria normalmente ou mecanicamente, "copiadamente"? já que outro respondente diz que "[...] quando necessário eu registro de acordo com a ficha técnica do livro" (Respondente N, formado em Tecnologia de Processamentos de Dados, atua na Rede Estadual de Ensino).Fica a incógnita sobre a abrangência e as especificidades destes cursos técnicos. Houve por outro lado, aquele que disse: "no momento ainda não dispomos destes serviços. Os mesmos serão realizados num futuro próximo". (Respondente T, formado em Administração de Empresa, atua na Rede Estadual de Ensino). Mas, qual seria este "futuro próximo"? O remanejamento de um profissional sem formação? Infelizmente somos condicionados a acreditar nesta solução.

No geral, as respostas de como são realizados os serviços técnicos de um Bibliotecário, ficaram em consonância entre os participantes da rede estadual, pois responderam em sua maioria que tais serviços estão sendo mantidos de acordo com o já existente, quando eles começaram a trabalhar na Biblioteca, ou mesmo baseados em seus conhecimentos adquiridos pelos cursos técnicos oferecidos pelo governo. Já os participantes da rede municipal, relataram ser a Biblioteca Pública Municipal de Londrina, 
a responsável pelos serviços técnicos, o que demostra ser o mais correto, pois de fato são Bibliotecários a frente de suas competências.

Porém, foi dito que os serviços oriundos da Biblioteca Pública "[...] é um trabalho demorado, pois atende a todas a bibliotecas escolares do município" (Respondente L, formado em Pedagogia, atua na Rede Municipal de Ensino). Em vista disso, talvez seja o motivo pelo qual leva um dos integrantes a não respeitar esta prática, já que este assume que "com muita dificuldade é feito a catalogação porque grande parte do tempo dedico ao trabalho pedagógico mas é realizado não como deveria, nas horas que sobram e com o apoio da biblioteca central e dos colegas (professores)" (Respondente K, formado em Curso Normal Superior, atua na Rede Municipal de Ensino).

Neste caso, o erro é duplo, não só o funcionário sem formação, como também os demais colegas professores, ajudam na catalogação, devido a deficiência encontrada pelo processo realizado por parte da Biblioteca Municipal.

Concernente as atividades de competência profissional de um Bibliotecário, foi listado uma sequencia de atribuições, da qual o participante na questão deveria assinalar "sim ou não" para: "Quais destas atividades abaixo você julga ser de sua competência profissional?" (№ 14) e posteriormente assinalar também "Quais destas atividades abaixo você de fato realiza, ou seja, quais fazem parte da rotina de serviços da Biblioteca em que trabalha?" (№ 15)

Nestas atribuições, os participantes da rede estadual, principalmente aqueles que realizaram o curso técnico oferecido pelo governo, assinalaram nas duas ocasiões que julgam ser de sua competência profissional e também da rotina de serviço da Biblioteca em que atua, as atividades como: elaborar política de desenvolvimento de coleções; realizar serviços técnicos como catalogação, classificação, indexação, etc.; oferecer serviço de referência e oferecer serviço de Disseminação Seletiva da Informação (DSI).

No entanto, houve controvérsias com os demais participantes da rede estadual, sem formação e sem o curso técnico, pois foi assinalado, por exemplo, ser de sua competência profissional a elaboração de política de desenvolvimento de coleções, mais, no entanto, não realiza na prática este serviço, nem tão pouco analisa a necessidade informacional da comunidade escolar. Já nas Bibliotecas da rede municipal, as atividades assinaladas em ambas as questões, isto é, as que julgam de sua competência e as que de fato realizam na Biblioteca, foram aquelas relacionadas com o de fomento a leitura e ação cultural, as de atendimento ao usuário e a de procedimentos de conservação e 
restauração do acervo, salvo aquele que, como mencionado, diz realizar serviços de catalogação. Nas Bibliotecas da rede particular de ensino, estas atividades se diferenciaram quando pedido para assinalar somente as que de fato são realizadas no seu ambiente de trabalho, pois todas as atribuições listadas no primeiro quadro foram entendidas como pertencentes a sua área de competência profissional, porém algumas ainda são desenvolvidas, como por exemplo, Política de Marketing, Política de Desenvolvimento de coleção, Disseminação Seletiva da Informação e Administração de Recursos Orçamentários.

Depois de levantado estas atribuições na questão de número 14 e 15, foi solicitado que: "Com base nas respostas assinaladas como "sim" na questão anterior, descreva de modo sucinto como ocorrem na prática às atividades que são desenvolvidas especificamente com os alunos no dia-a-dia da Biblioteca?" (№ 16), porém não foi obtido somente descrição das relacionadas aos alunos, mais também as de cunho administrativo e tecnicista, que, diga-se de passagem, são de extrema importância também. Mas, ocorre que isso evidenciou principalmente nas falas dos Bibliotecários, a demonstração do tal apego pelas técnicas, tão comentadas nos variados estudos. Apesar disso, revelou que na mesma proporção, até os funcionários que não são Bibliotecários, enfatizaram as atividades técnicas, já que alguns respondentesdeclararam realizá-las, seja informalmente, seja pelos conhecimentos dos cursos técnicos.

Ainda de acordo com a observação feita sobre o tecnicismo, um dos participantes merece felicitações, pois na questão abordada sobre as atividades desenvolvidas com os alunos, embora não fosse este o contexto, foi respondido que "a biblioteca escolar realiza quase todas as atividades que as outras bibliotecas, porém de um modo mais sucinto. A catalogação é simplificada, a busca pela informação é de forma mais descontraída, sem termos técnicos, mas de maneira que qualquer criança entenda." (Respondente E, formado em Biblioteconomia, atua na Rede Particular de Ensino).

Todavia, é necessário que ocorra de forma efetiva o desprendimento por parte dos profissionais que concentram como prioritária apenas suas técnicas biblioteconômicas, pois nos dias atuais em que formar leitor tem se apresentado como uma meta a ser alcançada pelos educadores, certamente Bibliotecários inclui-se como participantes diretos desta expectativa (QUINHÕES, 1999).

Quanto as características do que os respondentes consideram importante para sua atuação na Biblioteca, houve uma unanimidade, pois acreditam ser necessário estar 
atualizado, ser criativo, trabalhar em equipe, ter ética, iniciativa, senso de organização, liderança e flexibilidade.

Quadro 3 - Terceira Parte - Conhecimentos sobre a Lei 12.244/10

11- É de seu conhecimento a existência da Lei 12.244/10 que universaliza a criação de Bibliotecas Escolares nas instituições de ensino do país públicas e privadas?

( ) Sim ( ) Não

12- Esta Lei (dentre outros) determina que seja efetivada a universalização das Bibliotecas em um prazo máximo de dez anos, respeitando a profissão de Bibliotecário. Você concorda que é importante haver Bibliotecas e Bibliotecários nas escolas?

( ) Sim ( ) Não

13- Você julga importante que ocorra a concretização desta referida Lei?

( ) Sim. Por quê? ( ) Não. Por quê?

20- Em sua opinião a lei 12.244/10 representa uma possível efetividade no que tange a melhorias para as bibliotecas escolares, bem como para o profissional Bibliotecário?

Fonte: Dados extraídos da pesquisa.

Foram relacionadas quatro perguntas a respeito da Lei $12.244 / 10$, para que os participantes contribuíssem com a análise acerca de sua relevância para a profissão e campo de trabalho do Bibliotecário.

Assim sendo, primeiramente foi perguntado: "É de seu conhecimento a existência da Lei 12.244/10 que universaliza a criação de Bibliotecas Escolares nas instituições de ensino do país públicas e privadas?” (№ 11), onde ficaram equilibradas as respostas entre sim e não, dentre aqueles que não eram Bibliotecários. Já entre os 10 participantes com formação especifica, todos disseram ter conhecimento.

Quando questionado sobre: "Esta Lei (dentre outros) determina que seja efetivada a universalização das Bibliotecas em um prazo máximo de dez anos, respeitando a profissão de Bibliotecário. Você concorda que é importante haver Bibliotecas e Bibliotecários nas escolas?" (№ 12), os 19 participantes responderam que sim, exceto um dos colaboradores, que embora não estivesse solicitando justificativa na pergunta, acrescentou por livre e espontânea vontade, que: "Cito não porque até o momento ainda a formação do bibliotecário não desenvolve o que mais valorizo para fomentar a leitura, $o$ profissional que tem o trato pedagógico e conhecimento do desenvolvimento psicológico e o usa nas horas do conto. Essa formação eu obtive nos cursos mensais que a prefeitura de Londrina oferece desde 2000." (Respondente K, formado em Curso Normal Superior, atua na Rede Municipal de Ensino). 
Já referente a questão (№ 13): "você julga importante que ocorra a concretização desta referida lei?" as respostas foram unânimes, todos disseram que sim e justificaram a pedido. Entre o consenso dos candidatos, as justificativas basicamente, foram pensadas em prol da melhoria do ensino-aprendizagem e da própria organização da Biblioteca, uma vez que nestes espaços, quase sempre as atividades funcionas sem muita vitalidade e se limitam a um acervo de pouca qualidade, salvo exceções.

Por fim, na última questão (№ 20): "Em sua opinião a lei 12.244/10 representa uma possível efetividade no que tange a melhorias para as bibliotecas escolares, bem como para o profissional Bibliotecário?", os participantes não dividiram opiniões quanto a possibilidade de não haver uma forma efetiva aplicação, e concordaram que esta lei é de extrema importância para a revitalização das Bibliotecas escolares, bem como para o profissional Bibliotecário.

Temos aqui duas proposições que envolve a Lei 12.244/10. Primeiro, a sua efetividade e segundo, a importância que ela representa para as Bibliotecas escolares e para o Bibliotecário. Assim, no que tange a efetividade da lei, foi argumentado que as leis brasileiras são deficientes quanto ao seu cumprimento, pois permanece apenas na teoria, visto que muitas distintas situações que deveriam ser respeitadas, não o são. Dessa maneira, esta lei, se não fiscalizada seria mais uma a ser "engavetada", já que muitas vezes o governo não aplica punições.Outro posicionamento tomado por alguns participantes, além da apreensão quanto à fiscalização, revelam o descontentamento em relação ao Conselho Regional de Biblioteconomia (CRB), argumentando que:

$\checkmark$ “[...] seria necessário a fiscalização por parte do CRB e ainda um sindicato efetivo, visto que no Paraná o Sindib está em Curitiba e Londrina fica desprovido de fiscalização e os patrões não pagam os pisos salariais indicados e ficamos sem nenhum amparo legal após estudarmos e nos especializarmos para uma atividade que não é valorizada, visto que existem pessoas sem formação ocupando o cargo em bibliotecas escolares". (Respondente C, formado em Biblioteconomia, atua na Rede Particular de Ensino);

$\checkmark$ "[...] com bibliotecas em todas as escolas no país o curso de Biblioteconomia será mais valorizado o que não vem ocorrendo hoje em dia, pois às vezes tem faltado mercado de trabalho, pois temos um conselho muito aquém do necessário, pois fica com sede em Curitiba, o que só nos faz cobrar a anuidade sem nos dar 
qualquer suporte aqui no interior, quem sabe assim eles se tornam um conselho mais atuante. (Respondente $\mathrm{H}$, formado em Biblioteconomia, atua na Rede Particular de Ensino).

Esta insatisfação demonstra a ansiedade que os profissionais Bibliotecários sentem a respeito da necessidade de mudanças em torno da constatação de que outros profissionais distintos ocupam os postos de trabalho nas Bibliotecas das escolas, gerando uma diminuição no campo de trabalho.

Isto é evidente, pois neste estudo a maioria dos participantes de escolas da rede estadual e da municipal, como já mencionado, não são Bibliotecários.

Com a fiscalização e real efetividade da lei, surge a confiança de dias melhores. "Acho que quando realmente a lei for cumprida, os bibliotecários serão vistos com outros olhos, por enquanto não temos valor nenhum, por que não existe este cargo na rede pública, como não existe, não fazemos falta..., pois ainda não pudemos mostrar a importância de nossa profissão". (Respondente E, formado em Biblioteconomia, atua na Rede Particular de Ensino).

Assim, não bastará o artigo $3^{\circ}$ exigir a presença do Bibliotecário, e também da própria Biblioteca na escola, se não houver averiguação necessária, pois a implantação das Bibliotecas só será completa quando atender a todos os requisitos, diga-se de passagem, são itens básicos dos quais não deveriam ser nem preciso a cobrança por meio de legislações.

Esta importância de fiscalização se dá pela abertura que a lei permite, pois mesmo sancionada e publicada, esta não se encontra regulamentada. Por isso, este fator incita certa arbitrariedade, uma vez que se ninguém reclamar pela aplicação de um direito garantido ficaremos a espera, e a mercê da vontade alheia de fazer acontecer. Em suma, devemos nos ater a fiscalização da Lei $12.244 / 10$ e protestar a fim de garantir a não concretização da aprovação final deste novo Projeto de Lei.

\section{CONSIDERAÇÕES FINAIS}

A pesquisa em questão analisou o tripé Biblioteca Escolar, Competências do Bibliotecário e a Lei 12.244/10, pois estes três elementos se relacionam diretamente entre si. 
Em especial no que tange o profissional Bibliotecário que atua nesta área, os resultados obtidos mostraram que há uma apropriação por parte de outros profissionais com variadas formações que atuam em Bibliotecas Escolares.

Sendo assim, os Bibliotecários de profissão, vão fixando seus afazeres e tornando isso natural, pois já não sentem mais a necessidade de reivindicar posto de trabalhos voltados para sua área de formação, até porque a Biblioteca Escolar é sugestiva para a integração das atividades educacionais.

Por isso, é imprescindível que se tenha conhecimento quão a profissão tem sofrido com a desapropriação feita por outrem, devido o simples fato da própria falta de informação do ofício alheio, e sem hipocrisias, pelo simples fato também de o próprio Bibliotecário não mostrar a extensão de suas capacidades, isto é, de suas competências.

Isso foi constatado nas verificações das respostas coletadas, pois se apurou que além de em sua maioria, os funcionários das Bibliotecas não serem Bibliotecários, parte destes com variadas formações, consideram dispensável a presença de um profissional Bibliotecário.

Foi argumentado por estes funcionários que os mesmos se dizem capazes de realizar tranquilamente os serviços de um Bibliotecário, enfatizando ainda que o Bibliotecário (com formação) não se encontra preparado pedagogicamente para trabalhar com a área educacional.

Quanto a isso, devemos admitir que o Bibliotecário precisa mudar certas concepções a respeito de si próprio, e começar a evidenciar sempre que possível, os seus feitos, pois foi por intermédio destas evidências que foi possível constatar o pensamento dos demais funcionários não Bibliotecários atuantes, de que, os Bibliotecários são sim, capacitados para entender que além das técnicas biblioteconômicas, é necessário haver atitudes envolventes com a educação, ou melhor dizendo, ter atitudes pedagógicas.

Especificamente sobre a Lei $12.244 / 10$, espera-se que "[...] com novas diretrizes sobre a instalação de bibliotecas em escolas, há de se conhecer e valorizar o trabalho dos bibliotecários." (OLIVEIRA, 2012, Não paginado).E para sua efetividade a falta de informação de como buscar recursos para concretizar a lei poderá apresentar um grande empecilho.

Lembrando, também, que haverá a questão da demanda pelos profissionais se a Lei assim se efetivar. 
De forma genérica, falta-lhes então ter consciência que é preciso fixar e desvendar seus afazeres e saberes em prol de sua identidade, pois no caso da estrutura - Biblioteca escolar, suas falhas são decorrentes de um contexto histórico, político e social que implica mudanças que não são unicamente responsabilidade do Bibliotecário escolar. Assim, enquanto profissionais especializados fazer a diferença cabe mesmo que individualmente.

Quanto a Lei 12.244/10, sem dúvida representa uma evolução para as Bibliotecas e Bibliotecários, pois sancionada permite que possamos requerer nossos direitos, em caso da falta de aplicação e efetivação, visto que isto se mostrou com grande preocupação principalmente entre os Bibliotecários. Não se deve negar, que na maioria dos participantes da pesquisa, estes se mostraram solidários com a melhoria que esta Lei pode oferecer.

Entretanto, mesmo com tantos aspectos positivos que a lei tem representado, existe o outro receio, já mencionado, o Projeto de Lei no 3044/2008 que está em trâmite no Senado Federal. Está, porém, será necessário aguardar o seu andamento.

Dessa forma, sugere-se neste momento, que dependendo da proporção que este assunto tomar, sem dúvida se mostra como um tema interessante para novas pesquisas. Fica o palpite.

\section{REFERÊNCIAS}

AGENCIA BRASIL. 2010. País precisa construir 25 Bibliotecas por dia para cumprir nova lei. Disponível em: <http://www1.folha.uol.com.br/saber/744506-pais-precisaconstruir-25-Bibliotecas-por-dia-para-cumprir-nova-lei.shtml>. Acesso em: 06 ago. 2012.

AGÊNCIA DO RÁDIO. Educação: lei obriga Biblioteca em toda escola. 2012. Disponível em: <http://www.agenciadoradio.com.br/noticia.php?codigo_noticia=PCFB110003> Acesso em: 06 ago. 2012.

ALMEIDA JÚNIOR, Oswaldo Francisco de. Bibliotecário escolar: seu perfil, seu fazer. In: SILVA, Rovilson José da; BORTOLIN, Sueli (Org.). Fazeres cotidianos na Biblioteca escolar. São Paulo: Polis, 2006. p. 43-54.

\section{BALMANT, Ocimara. Em $\mathbf{7 2 , 5 \%}$ das escolas não há biblioteca, lei prevê} obrigatoriedade até 2020. 2013. Disponível em:

<http://www.estadao.com.br/noticias/impresso,em-725-das-escolas-nao-ha-biblioteca-leipreve-obrigatoriedade-ate-2020-,987556,0.htm>. Acesso em: 17 jun. 2013. 
BRASIL, Ministério da Educação e Cultura. Avaliação das Bibliotecas Escolares no Brasil, 2011. Disponível em: <http://www.oei.es/bibliobrasil.pdf>. Acesso em: 14 maio 2012.

BRASIL, Ministério do Trabalho e Emprego. Classificação Brasileira de Ocupações. 2002. Disponível em:

<http://www.mtecbo.gov.br/cbosite/pages/relatorio/relatorioTemplateWordFamilia.jsf>. Acesso em: 14 ago. 2012.

BRASIL. Constituição (1988). Constituição da República Federativa do Brasil. 31. ed. São Paulo: Saraiva, 2003.

BRASIL. Secretaria de Educação Fundamental. Parâmetros curriculares nacionais: língua portuguesa. Brasília: MEC, 1998.

BRASIL. Senado Federal. Lei 12.244, de 24 de Maio de 2010. Dispõe sobre a universalização das bibliotecas nas instituições de ensino do País. Diário Oficial da União. 25 maio de 2010; Seção 1, p. 3. Disponível em:

<http://www.planalto.gov.br/ccivil_03/_Ato2007-2010/2010/Lei/L12244.htm>. Acesso em: 17 jan. 2012.

BRASIL. Senado Federal. Lei 9.394 de 24 de dezembro de 1996. Disponível em:<http://www.planalto.gov.br/ccivil_03/Leis/L9394.htm>. Acesso em: 14 ago. 2012.

BRASIL. Senado Federal. Lei 10.172 de 9 de janeiro de 2001. Disponível em:<https://www.planalto.gov.br/ccivil_03/leis/leis_2001/l10172.htm>. Acesso em: 14 ago. 2012.

COMPETÊNCIAS para os bibliotecários do século 21 - Adaptado do relatório "Competencies for SpecialLibrariansofthe 21st Century" da SLA (1996). Disponível em: <http://bibliodata.ibict.br/geral/docs/padronizacao.pdf>. Acesso em 26 mar. 2012.

CÔRTE, Adelaide Ramos; BANDEIRA, Suelena Pinto. Biblioteca Escolar. Brasília: Briquet de Lemos, 2011.

FARIAS,Christianne Martins; CUNHA, Miriam Vieira da. O bibliotecários escolar e suas competências. Info. \& Soc., João Pessoa, v. 19, n. 1, p. 29-35, 2009. Disponível em: <http://www.ies.ufpb.br/ojs/index.php/ies/article/view/1787/2685>. Acesso em: 26 mar. 2012;

FRAGOSO, Graça Maria. Biblioteca na escola. Rev. ACB: Biblioteconomia, Santa Catarina, SC, v. 7, n. 1, p. 124-131, 2002. Disponível em:

<http://dici.ibict.br/archive/00000883/01/Rev[1].AC-2005-78.pdf>. Acesso em: 17 jan. 2012.

GARCEZ, Eliane Fioravante. O bibliotecário nas escolas: uma necessidade. Revista ACB: Biblioteconomia em Santa Catarina, Florianópolis, v. 12, n. 1, p. 27-41, jan./jun., 2007. Disponível em: <http://revista.acbsc.org.br/racb/article/view/492/633>. Acesso em: 17 jan. 2012. 
JORNAL o povo. Professores reclamam de medida "surpresa" da SME. Disponível em:

<http://www.opovo.com.br/app/opovo/politica/2013/04/19/noticiasjornalpolitica,3041698/pr ofessores-reclamam-de-medida-surpresa-da-sme.shtml>. Acesso em 17 jun. 2013.

LOBBE NETO, Antonio Adolpho. Lobbe Neto: PDSB. Disponível em:

<http://www.lobbe.com.br/site/trajetoria.php>. Acesso em: 12 ago. 2012.

MEGHNAGI, Saul. A competência profissional como tema de pesquisa. Educ. Soc., Campinas, v. 19, n. 64, set. 1999. Disponível em:

$<$ http://www.scielo.br/scielo.php?script=sci_arttext\&pid=S0101-

73301998000300003\&lng=pt\&nrm=iso >. Acesso em: 01 fev. 2012.

OLIVEIRA, Patrícia Cristina Rodrigues de. Lei 12.244/10, o profissional bibliotecário e a biblioteca escolar. 2012. Disponível em:

<http://www.revistaoprofessor.com.br/wordpress/?p=631>. Acesso em: 02 abr. 2012.

PORTAL DE ATIVIDADE LEGISLATIVA. PLC - Projeto de lei da câmara no $\mathbf{3 2 4}$ de 2009. Disponível em:

$<$ http://www.senado.gov.br/atividade/materia/detalhes.asp?p_cod_mate=95219>. Acesso em 02 abr. 2012.

QUINHÕES, Maura Esandola Tavares. Biblioteca escolar: sua importância e seu espaço no sistema educacional do Estado do Rio de Janeiro. In: VIANNA, Márcia Milton; CAMPELLO, Bernadete; MOURA, Victor Hugo Vieira. Biblioteca escolar: espaço de ação pedagógica. Belo Horizonte: EB/UFMG, 1999. p. 178-182.

RÁDIO CAMÂRA. Lei que obriga oferta de Biblioteca em escolas está em vigor. 2010. Disponível em: <http://www2.camara.gov.br/radio/materias/ULTIMAS-NOTICIAS/386050LEI-QUE-OBRIGA-OFERTA-DE-BIBLIOTECA-EM-ESCOLAS-EST\%C3\%81-EM-VIGOR\%2802\%2726\%22\%29.html>. Acesso em: 06 ago. 2012.

RODRIGUES, Nêmora. 12 de março: dia do bibliotecário. 2011. Disponível em: <http://ced07taguatinga.blogspot.com.br/2011/03/12-de-marco-dia-do-Bibliotecario.html>. Acesso em: 06 ago. 2012.

RUSSO, Mariza. Fundamentos em biblioteconomia e ciência da informação. Rio de Janeiro: E-papers, 2010.

SALGADO, Denise Mancera, BECKER, Patrícia. O Bibliotecário no olhar do público escolar. Encontros Bibli, Florianópolis, v. 3, n. 6, set. 1998. Disponível em:

<https://periodicos.ufsc.br/index.php/eb/article/view/18/5033>. Acesso em 06 ago. 2012.

SILVA, Mateus de Oliveira. Gestão de pessoas através do sistema de competências: estratégias, processos, desempenhos e remuneração. Rio de Janeiro: Qualitymark, 2005.

TAVARES, Denise Fernandes. A Biblioteca escolar. São Paulo: Lisa, 1973. 


\title{
Title
}

Professional skills of school librarian: reflections from the law 12.244/10

\begin{abstract}
Introduction: Refers to the tripod School Library, Librarian Skills and the law 12.244/10 which provides for the universalization of school libraries. Reflects the conflict situation of the majority of the reality of School Libraries and the absence of professional librarian.

Objective: It aims to analyze the importance of professional skills developed by the school librarian. Asks to which thought and vision that school libraries professionals, librarians or not, have to respect the law.

Methodology: We used the exploratory and descriptive and qualitative approach, in which the survey instrument consisted of a questionnaire administered to employees responsible for School Libraries research participants.

Results: The professionals working in the libraries of higher education institutions have investigated in various courses, where 20 libraries, only 10 have the librarian. Respondents mostly agree on the importance of a trained librarian and the implementation of Law 12.244/10 should be reviewed as it is not regulated.

Conclusions: It is considered that the professional Librarian often suffers from the generalized concepts by those who are unaware of the profession. However, the Act suggests an expectation of improvement, it is applied and required by citizens.
\end{abstract}

Keywords: School Library. Professional Competence. Schoollibrarian. Law 12.244 /10.

\section{Título}

Habilidades profesionales de bibliotecaria de la escuela: reflexiones de laley 12.244 /10

\section{Resumen}

Introducción: Se refiere a las habilidades bibliotecario trípode Biblioteca de la Escuela, y la ley 12.244/10, que prevé la universalización de las bibliotecas escolares. Refleja la situación de conflicto de la mayor parte de la realidad de las bibliotecas escolares y la ausencia de bibliotecario profesional.

Objetivo: El objetivo es analizar la importancia de las habilidades profesionales desarrolladas por el bibliotecario de la escuela. Pide a la que el pensamiento y la visión que las bibliotecas escolares profesionales, bibliotecarios o no, tienen que respetar la ley.

Metodología: Se utilizó el enfoque exploratorio y descriptivo y cualitativo, en el que el instrumento de la encuesta consistió en un cuestionario aplicado a los empleados responsables de participantes en la investigación bibliotecas escolares.

Resultados: Los profesionales que trabajan en las bibliotecas de instituciones de educación superior han investigado en diversos cursos, en los que 20 bibliotecas, sólo 10 tienen el bibliotecario. Los entrevistados coinciden en su mayoría en la importancia de un bibliotecario capacitado y la aplicación de la Ley 12.244 /10 debe ser revisado, ya que no está regulado. 
Conclusiones: Se considera que el bibliotecario profesional sufre a menudo de los conceptos generalizados por aquellos que no son conscientes de la profesión. Sin embargo, la Ley indica una expectativa de mejora, que se aplica y requerida por los ciudadanos.

Palabras clave: biblioteca escolar. Competencia Profesional. Bibliotecario de la escuela. Ley 12.244/10.

Recebido em: 12.11 .2014

Aceito em: 22.12.2014 